\title{
SOBRE LINGUAGEM COMO FIO CONDUTOR DAS REFLEXÕES DE GIORGIO AGAMBEN
}

\author{
Benjamim Brum Neto
}

Resumo: $\mathrm{O}$ artigo pretende abordar a linguagem como motor fundamental das reflexões de Giorgio Agamben, sejam elas pertinentes à filosofia, teologia, direito ou política. Para isso o artigo se divide em duas partes. Na primeira, pretendemos mostrar, sobretudo a partir de textos anteriores à série Homo sacer, especialmente os presentes na coletânea $A$ potência do pensamento, de que forma o pensamento sobre a linguagem influencia a compreensão de Agamben sobre o conceito de filosofia, de teologia e de tradição. Já na segunda parte pretendemos explorar de que forma, de acordo com Agamben, a operação jurídico-política fundamental de nossa tradição está vinculada à forma como pensamos até hoje a relação do homem com o logos. Para Agamben, a estrutura de exceptio corresponde à estrutura originária do acontecimento de linguagem.

Palavras-chave: linguagem - política - direito - exceção.

$$
\begin{array}{r}
\text { Portanto, a linguagem é a nossa voz, a nossa linguagem. } \\
\text { Como agora falas, isto é a ética - Agamben }
\end{array}
$$

\section{INTRODUÇÃO}

A presente investigação pretende expor alguns apontamentos pertinentes à relação entre linguagem, política e direito na obra de Giorgio Agamben. Nosso objetivo é compreender os desdobramentos do tema da linguagem nos trabalhos do filósofo italiano mais explicitamente voltados à temática do direito e da política. Dentre as conclusões, entenderemos de que forma a reflexão de Agamben sobre a linguagem fornece um modelo de estrutura e de fundamento à investigação sobre a política na série Homo sacer, o que fica muito claro quando o filósofo afirma que "a estrutura particular do direito tem seu fundamento nesta estrutura pressuponente da linguagem humana"2. A pretensão de abordar

\footnotetext{
${ }^{1}$ Doutorando em filosofia pela Universidade Federal do Paraná sob orientação do professor doutor André Duarte. E-mail: benjamim.brum@gmail.com. O presente trabalho foi realizado com apoio da Coordenação de Aperfeiçoamento de Pessoal de Nível Superior - Brasil (CAPES) - Código de Financiamento 001.

2 AGAMBEN, Homo sacer: o poder soberano e a vida nua, p. 29.
} 
a linguagem nos textos, por assim dizer, políticos de Agamben tem por objetivo justamente mostrar que as reflexões ali presentes são devedoras de uma preocupação maior com a linguagem em sua filosofia. A busca dessa confirmação nos textos que o filósofo define como uma "arqueologia da política"3 se justifica pelo fato de que o dispositivo da exceção (exceptio), e essa é desde já uma das nossas hipóteses, tem seu paradigma na estrutura pressuponente da linguagem. Isso faz com que a reflexão sobre a política - mas também sobre o direito e a ética - em Agamben tenham como estrutura e fundamento um paradigma linguístico. A linguagem também aparece como um fator determinante em $O$ sacramento da linguagem, onde, no contexto de uma arqueologia do juramento, Agamben define a própria performatividade da linguagem como aquilo que, através da veridicção, torna possível as instituições humanas, como é o caso do direito. O modo arqueológico de consideração das nossas estruturas político-institucionais conecta-se, nesse sentido, diretamente às considerações sobre a linguagem. As ramificações em tantas disciplinas presentes na série Homo sacer - da estética à ética, da metafísica à teologia, da política ao direito - encontrariam no questionamento de nossa experiência com a linguagem, assim, o seu lugar, o seu topos.

\title{
LINGUAGEM E POLÍTICA COMO TEMAS CENTRAIS EM AGAMBEN
}

\author{
Aquilo que une a culpa e a pena não é outra \\ coisa senão a linguagem - Agamben
}

Linguagem e política parecem ser duas constantes na reflexão de Giorgio Agamben. Sobretudo em seus primeiros livros, publicados na década de 1970 e 1980, o filósofo estabelece relações, muitas delas inusitadas, entre linguística, psicanálise e filosofia, mas também literatura, teologia e estética, de modo que sempre podemos extrair dessas obras interessantes reflexões sobre a linguagem e sobre a ética. A partir dos anos 1990, sobretudo em 1995 com a publicação do primeiro volume da série Homo sacer, poder-se-ia argumentar que finalmente o autor estaria tratando de política, como uma espécie de segunda fase de seu pensamento. O que pretendemos mostrar com a pesquisa que desenvolveremos é que essa ideia é falsa. A reflexão presente em Homo sacer entretém uma relação direta com as primeiras obras do autor, de modo que podemos entendê-las como uma espécie de prolongamento ou de desenvolvimento das teses anteriormente trabalhadas por ele. Em Homo sacer há reflexões de suma importância para pensarmos a linguagem; e por outro lado, o diagnóstico que Agamben realiza das democracias contemporâneas e das sociedades espetaculares dialoga diretamente com essa preocupação primeira do filósofo com ela:

O plano de imanência sobre o qual se constitui a nova experiência política é a extrema expropriação da linguagem realizada pelo Estado espetacular. Enquanto, de fato, no velho regime, o estranhamento da essência comunicativa do homem tinha a sua substância em um pressuposto que

${ }^{3}$ AGAMBEN, O uso dos corpos, p. 295. 
funcionava como fundamento comum (a nação, a língua, a religião...), no Estado contemporâneo é essa mesma comunicabilidade, essa mesma essência genérica (isto é, a linguagem) que se constitui em uma esfera autônoma na própria medida em que se torna o fator essencial do ciclo produtivo. O que impede a comunicação é, assim, a própria comunicabilidade, os homens são separados daquilo que os une. ${ }^{4}$

Diante desse diagnóstico, nosso interesse é justamente o de avaliar os modos segundo os quais para Agamben pensar a linguagem implica pensar a política.

A linguagem aparece tematizada em vários textos do filósofo italiano, consistindo num topos que persiste desde suas reflexões mais antigas - como por exemplo no caso do ensaio que o autor enviara à Hannah Arendt intitulado Sobre os limites da violência ${ }^{5}$ - até textos

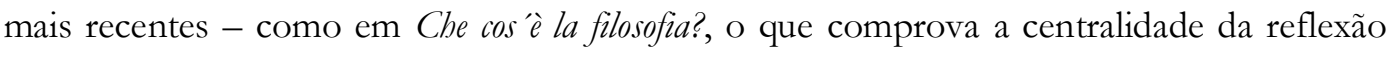
sobre a linguagem em sua obra. Apesar disso, conforme argumentaremos, o mesmo se dá em relação à política. É o que podemos depreender da seguinte afirmação: “Os gregos, que inventaram quase todos os conceitos dos quais atualmente fazemos uso para exprimir nossa experiência da política, designavam precisamente com o termo polis o modo de vida fundado sobre a palavra e não sobre a violência" (AGAMBEN, 2017a). Com o propósito de circunscrever o problema da violência em nossa tradição, Agamben de partida relaciona nossa experiência política ao fundamento da palavra. É precisamente essa conexão entre linguagem e política que permanecerá como tema central dos trabalhos de Agamben, se não sempre de maneira explícita enquanto o objeto de investigação propriamente dito, ao menos como um recurso metodológico indispensável (nos referimos aqui à teoria das assinaturas) ou mesmo como um pano de fundo mais fundamental da análise que se está sendo feita. É isso que se vê em Homo sacer: o poder soberano e a vida nua, mas também em O sacramento da linguagem: uma arqueologia do juramento e Uso dos corpos, além de outras duas obras onde o vínculo entre linguagem e política aparece de forma bastante expressiva: A comunidade que vem e Meios sem fim: notas sobre a política.

Trabalharemos a partir da seguinte hipótese: as reflexões presentes em Homo sacer são decorrentes de uma preocupação mais fundamental com a linguagem, a qual determina o modo como Agamben se relaciona com a tradição ocidental. Acreditamos que o estudo da política a partir da linguagem nos permitirá uma melhor compreensão de algumas operações (inclusive as relativas ao método) ${ }^{6}$ que a arqueologia da política proposta pelo filósofo italiano visa, bem como do estatuto que a política ocupa na economia do seu pensamento.

${ }^{4}$ AGAMBEN, Meios sem fim: notas sobre a politica, p. 106.

5 AGAMBEN, "Sobre os limites da violência".

${ }^{6}$ A questão da metodologia que Agamben emprega em suas investigações filosóficas foi abordada pelo próprio autor em Signatura rerum: sur la méthode (2008), onde ele aborda três temas fundamentais à presente pesquisa, mas que não poderão ser abordados neste projeto: (i) o paradigma; (ii) teoria das assinaturas; (iii) a arqueologia filosófica. Além disso, como numa espécie de complementação a esse texto de metodologia, Agamben publicou recentemente na revista Critique um breve texto intitulado Principia hermeneutica (2017), onde o autor expõe alguns princípios que nortearam a formulação de suas investigações e de seus textos. Tratam-se de seis princípios: (i) Princípio de Benjamin-Ticonius; (ii) princípio de Feuerbach; (iii) princípio de Coleridge; (iv) primeiro e segundo princípio de Orígenes; (v) princípio de Overbeck-Foucault. 


\section{FILOSOFIA, TEOLOGIA, TRADIÇÃO E LINGUAGEM}

O próprio Agamben deixa clara a centralidade do problema da linguagem em suas reflexões no seguinte trecho extraído do prefácio à edição francesa de 1989, reproduzido na versão brasileira de Infância e história e intitulado Experimentum linguae:

Se para cada autor existe uma interrogação que define o motivum do seu pensamento, o âmbito que estas questões circunscrevem coincide sem resíduos com aquele para o qual é orientado todo o meu trabalho. Nos livros escritos e não escritos, eu não quis pensar obstinadamente senão uma única coisa: o que significa 'existe linguagem', o que significa 'eu falo'?7

Novamente em 1990, "numa recensão filosófica de uma obra de linguística", Agamben lança mão de uma tipologia apresentada por Jean-Claude Milner para distinguir "com precisão" o objeto da filosofia e o da linguística. Enquanto a linguística se ocuparia da língua, composta pelo factum linguae (o fato de que o que os homens falam é uma língua), pelo factum linguarum (o fato de que as línguas são diferentes mesmo pertencendo a uma classe homogênea) e pelo factum gramaticae (que corresponde ao verdadeiro fato constitutivo da linguística segundo o qual as línguas são passíveis de ser descritas em termos de propriedades), a filosofia se ocuparia, precisamente do factum loquendi, isto é, do fato de que a linguagem existe, assim como o fato de que existem seres falantes. Isso reservaria à filosofia a tarefa de abordar a linguagem a partir de sua pura existência.

Tendo em vista essa conexão intrínseca que o filósofo parece conferir à relação entre linguagem e filosofia, é preciso que entendamos o que Agamben entende por filosofia. Para o italiano, "a filosofia não é uma visão do mundo, mas uma visão da linguagem" que, paradoxalmente, "não pode ser simplesmente um discurso que tenha a linguagem como tema, uma metalinguagem que fale da linguagem" ${ }^{10}$. Isso quer dizer que a exposição filosófica não pode ser a exposição de suas ideias sobre a linguagem, das propriedades reais existentes dela, isto é, com um discurso significante sobre a linguagem, mas a exposição da ideia mesma da linguagem, a contemplação de sua existência mesma. Isso por sua vez explica a razão pela qual a filosofia não é, para Agamben, uma visão de mundo (caso em que ela se confundiria com uma ideologia $\left.{ }^{11}\right)$ : a filosofia deve ir além da significação e contemplar o lugar lógico original em que a linguagem existe à revelia de sua capacidade de significar.

\footnotetext{
${ }^{7}$ AGAMBEN, Infância e história: destruição da experiência e origem da história, p. 12.

${ }^{8}$ AGAMBEN, "Filosofia e linguística. Jean-Claude Milner: Introduction à une Science du langage", p. 51.

9 AGAMBEN, A ideia da linguagem, p. 27.

10 AGAMBEN, “A ideia da linguagem”, p. 27. Uma definição clássica de filosofia a qual Agamben explicitamente se filiou é aquela de Kojève: “a filosofia é o discurso que pode falar de tudo, na condição de falar também do fato que fala" (AGAMBEN, "Filosofia e linguística. Jean-Claude Milner: Introduction à une Science du langage”, p.52).

11 AGAMBEN, “A ideia da linguagem”, p. 28.
} 
É nesse sentido que a interrogação agambeniana sobre o modo de ser da linguagem se aproxima àquela de um "conteúdo da revelação", mostrando que em seu sentido mais fundamental, a linguagem seria para o filósofo uma abertura que permitiria que o que existe apareça ao homem. Conforme desenvolve Agamben, a tradição teológica compreende que o mistério da revelação é justamente o de que "a revelação de Deus é, ao mesmo tempo, o seu velamento" 12 . Essa mesma descrição serviria para a linguagem, entendida por Agamben como aquilo que se vela, que se esconde, ao mesmo tempo em que permite a revelação. Nesse sentido, a relação entre o homem e a linguagem pode ser caracterizada da seguinte forma: "o homem pode revelar o existente através da linguagem, mas não pode revelar a própria linguagem"13. O que aparece como uma comparação entre linguagem e revelação logo se torna em Agamben uma única coisa: a "revelação não significa este ou aquele enunciado sobre o mundo, não aquilo que se pode dizer através da linguagem, mas que a palavra, que a linguagem $e^{, 14}$.

Além disso, pelo fato de que a linguagem ocupa essa posição privilegiada de abertura do mundo ao homem, ela seria o meio absoluto do pensamento, isto é, única mediação imediata ${ }^{15}$ possível no que toca o homem, mas que por sua vez serve de mediação a qualquer tipo de conhecimento, a qualquer tipo de objeto, seja ele de que disciplina (mathemata) for. A caracterização da linguagem como mediação imediata também revela um outro aspecto da concepção de linguagem em Agamben, marcadamente devedora de Heidegger e de Benjamin $^{16}$ : a impossibilidade de ser instrumento. É à luz dessa concepção de filosofia que atribui à linguagem o lugar de arché (de princípio e fundamento), que Agamben parece entender ser possível uma libertação de todo pressuposto. Se a filosofia contemporânea já tomou, de um modo geral, consciência do fato de que a linguagem é o pressuposto insuperável ${ }^{17}$, agora, para não recair no "diferimento infinito" 18 seria preciso indicar o lugar lógico em que a linguagem tem-lugar, prévio à significação, onde ela seria pura medialidade, a partir de onde ela possibilitaria aos homens a abertura, i. e., o surgimento do mundo. É essa mesma indicação do ter-lugar da linguagem, na pura contemplação de sua existência, que Agamben situa aquilo que é comum entre os homens e que torna possível a comunidade humana. Conforme o filósofo afirma em Meios sem fim:

se aquilo que os homens tivessem a comunicar fosse sempre e apenas uma coisa, jamais haveria política propriamente, mas unicamente troca e conflito, sinais e respostas; mas como o que os homens tem a comunicar é, antes de

\footnotetext{
12 AGAMBEN, “A ideia da linguagem”, p. 24.

13 AGAMBEN, “A ideia da linguagem”, p. 24.

14 AGAMBEN, “A ideia da linguagem”, p. 25 (grifo nosso).

${ }^{15}$ Vale notar que essa mesma característica de "mediação imediata" que Agamben atribui à linguagem parece ser a característica que Schmitt atribui ao nómos em oposição à sua tradução como "lei”" que por sua vez é definida por Schmitt como "mediação rigorosa". Cf. AGAMBEN, Homo sacer: o poder soberano e a vida nua, p. 39.

16 SALZANI, "Il linguaggio è il sovrano: Agamben e la politica del linguaggio", p. 269.

17 AGAMBEN, “A ideia da linguagem”, p. 28.

${ }^{18}$ Esse parece ser o princípio da crítica que Agamben endereça à hermenêutica de Gadamer e à desconstrução de Derrida. Cf. AGAMBEN, “A ideia da linguagem”, pp. 28-29.
} 
tudo, uma pura comunicabilidade (ou seja, a linguagem), então surge a política. ${ }^{19}$

Se isso se confirma, ao que tudo indica, diante da impossibilidade filosófica de se falar sobre a linguagem de um modo significante, a indicação da dimensão pré-significativa da linguagem parece ser o telos da filosofia de Agamben, o lugar lógico da pura medialidade a partir do qual linguagem e política se tornam possíveis.

Nesse sentido, Agamben não pode se furtar ao debate com a tradição, pois é também por meio do evento de linguagem que a tradição foi transmitida, o que só foi possível graças à própria “abertura que está em questão na linguagem, que é a linguagem, e que na linguagem constantemente supomos e esquecemos"20. A intuição de Agamben é a de que a reflexão sobre a tradição, seja ela filosófica, jurídica ou religiosa deve começar pela avaliação da transmissão primeira, a partir da qual as transmissões significantes podem ocorrer, que não é outra senão a transmissão da própria linguagem. Portanto, nos parece que qualquer reflexão sobre o pensamento de Agamben tem como ponto de partida a linguagem.

Seguimos aqui uma intuição já presente em alguns comentadores de Agamben, dentre eles Murray (2010), Coccia (2017), D’Alonzo (2012) e Salzani (2015), segundo a qual é enquanto filósofo da linguagem que Agamben se relaciona com questões relativas ao ser, à política, ao direito e à literatura ${ }^{21}$. Nos opomos, portanto, a uma leitura tradicional encabeçada no Brasil sobretudo pelo livro de Edgardo Castro Introdução à Giorgio Agamben: uma arqueologia da potência (2012) que assume a tese de que a continuidade da obra de Agamben responde a uma preocupação com uma "arqueologia da potência". Segundo Castro: "ao menos ao nosso modo de ver, é possível traçar uma linha que vai desde $O$ bomem sem conteúdo até seu trabalho sobre o método, Signatura rerum. Essa linha está ocupada pela questão da potência ou, para sermos mais precisos, pela problemática aristotélica da potência"22. Embora de fato a leitura de Agamben da relação entre potência (dynamis) - traduzida como potência de ser ou de não-ser (adynamia $)^{23}$ - e ato (energia) seja de suma importância no percurso dos trabalhos de Agamben, é a linguagem que fornece o paradigma para o modo como Agamben lida com a trama do pensamento ocidental, com sua tradição, com seu dito e seu não-dito, seu pensado e seu impensado. Nesse sentido, ao nosso ver, desde 1968 há em Agamben um questionamento ininterrupto sobre o ser da linguagem ${ }^{24}$ e a releitura que Agamben realiza da potência aristotélica aparece como uma das figuras que contribui para a reflexão agambeniana sobre a experiência da linguagem feita pelo vivente homem. Assim sendo, se há um fio condutor na obra de Agamben, ele só pode ser representado pelo tema

${ }^{19}$ AGAMBEN, Meios sem fim: notas sobre a politica, pp. 90-91.

${ }^{20}$ AGAMBEN, “A coisa mesma”, p. 27.

${ }^{21}$ MURRAY, Giorgio Agamben, p.5

22 CASTRO, Introdução a Giorgio Agamben: uma arqueologia da potência, p. 10.

${ }^{23}$ Já há pesquisas que buscam mostrar a influência de autores como Averróis. Cf. KARMY, Políticas de la Excarnación.

24 “[D] esde un artículo del año 1968, cuyo título era L'albero di Babele, Agamben sostuvo que, por el contrario, es en el lenguaje donde el hombre 'se acerca más al problema de su propio estar-en-el-mundo, hallando de nuevo, cada vez, su estado fundamental frente al ser' (D’ALONZO, “El origen de la nuda vida: política y lenguaje en el pensamiento de Giorgio Agamben”, p. 101). 
da linguagem. Portanto, seguindo Coccia, entendemos que se a reflexão do século XX faz da linguística a "ciência-piloto" das ciências humanas, isto é, a emprega como um modelo a ser seguido de ciência para a decodificação do real, Agamben é o filósofo que radicaliza essa tendência. Agamben situa a linguagem no fundamento mesmo do pensamento filosófico, fazendo dela não apenas "o meio absoluto de todo pensamento, mas também seu objeto e, sobretudo, seu sujeito/tema" 25 .

\section{POLÍTICA, DIREITO E LINGUAGEM}

Em qualquer âmbito o pensamento do nosso tempo se encontra confrontado com a estrutura da exceção - Agamben

Na seção anterior buscamos mostrar que Agamben é, antes de tudo, um filósofo que reflete sobre a linguagem. Estando, agora, munidos dos argumentos que fazem da linguagem o tema comum que permite ao filósofo pensar diversos campos do conhecimento - vimos até agora como a linguagem é constitutiva da noção de filosofia, mas também de teologia e de tradição para ele -podemos agora nos voltar às obras de caráter explicitamente político e ver de que forma também nelas a reflexão sobre a linguagem é essencial.

Talvez o primeiro e mais essencial indício do que poderíamos quase aventar ser um indicativo do estatuto de imanência entre linguagem e política em Agamben (lembrando que também para Walter Benjamin linguagem e política estão no reino dos meios, e não no reino dos fins) consta já na discussão com Aristóteles, na introdução de O poder soberano e a vida nua. Após mostrar que "a simples vida natural é, porém, excluída, no mundo clássico, da pólis propriamente dita e resta firmemente confinada, como mera vida reprodutiva, ao âmbito do ôkos" 26 , Agamben questiona o estatuto do termo "político" na célebre definição aristotélica politiken zôon (1253a, 4). A respeito disso o filósofo italiano não pode se furtar à remissão à linguagem:

político não é um atributo do vivente como tal, mas é uma diferença específica que determina o gênero zôon (logo depois, de resto, a política humana é distinguida daquela dos outros viventes porque fundada, através de um suplemento de politização ligado à linguagem, sobre uma comunidade de bem e de mal, de justo e de injusto, e não simplesmente de prazeroso e doloroso). ${ }^{27}$

25 COCCIA, "Quodlibet. Logique et physique de l'être quelconque”, p. 70. Talvez Coccia tenha apelado à ambiguidade do termo em francês, pois a palavra "sujet" pode ser traduzida tanto por "tema", "questão", "assunto" quanto "sujeito".

${ }^{26}$ AGAMBEN, Homo sacer: o poder soberano e a vida nua, p. 10.

27 AGAMBEN, Homo sacer: o poder soberano e a vida nua, p. 10. 
Se de um modo geral em seus trabalhos Agamben se volta à impossível, porém necessária tarefa de expor a linguagem (factum loquendi, i. e., que há linguagem), neste trecho ela, a linguagem, aparece na figura de um "suplemento de politização" que funda o modo de ser político específico do vivente homem, ou melhor, a diferença específica da política que constitui a "natureza" do homem. ${ }^{28}$ Isso se deve ao fato de que, enquanto um atributo, a política, para Aristóteles, não é algo específico do homem. Também nesse sentido afirma Cassin que, "Aristóteles estabelece, assim, uma continuidade natural entre os animais e os homens, confirmada pelo fato de que existem outros 'animais políticos' além do homem". ${ }^{29}$ Logo, para que haja uma efetiva diferença entre a política do homem e a dos demais viventes, a definição de vida gregária é insuficiente, pois ela toma a política, nos termos de Agamben, como um atributo. E é isso que leva Agamben a destacar o papel da linguagem no fundamento da diferença específica do homem, isto é, aquilo que o torna o "mais político" dentre os viventes. A diferença então reside no fato do homem se politizar por meio do logos, e não apenas por meio de sons vocais, como no caso dos animais. Essa ligação entre política e linguagem marcada pela diferença específica do fundamento da linguagem do homem aparece bastante claramente já no ensaio O fim do pensamento, de 1982, quando ele afirma:

Acontece como quando caminhamos no bosque e, subitamente, surpreendenos a variedade inaudita das vozes animais. Silvos, trilos, chilros, lascas de lenha e metais estilhaçados, assobios, cicios, estrídulos: cada animal tem seu som, nascido imediatamente de si. Ao fim, a nota dúplice do cuco ri de nosso silêncio, divulgando nosso ser insustentável, o único sem voz no coro infinito das vozes animais. Então, provamos do falar, do pensar. ${ }^{30}$.

Trata-se, nos parece, de uma referência direta à relação entre os sons vocais e o logos presentes na Política de Aristóteles, que é também citado por Cassin:

A razão pela qual o homem é um animal mais político do que qualquer abelha ou animal gregário é evidente: a natureza, como dissemos, não faz nada em vão, ora, o homem é o único entre os animais a ter o logos. Sem dúvida, os

28 A respeito da natureza do homem, levando-se antes de tudo a noção de natureza própria de Aristóteles, Francalanci afirma: “Ao contrário, como o 'natural' do humano, isto é, como a sua marca distintiva, é possível dizer que o homem se move em direção a si próprio, ou seja, que ele já aconteceu inteiramente, desde sempre, mesmo nas modalidades de coexistência mais primeiras ou "primitivas". Neste sentido, o homem encontra o animal, mas desde já marcado pelo signo de uma diferença não explicitada: o homem é homem como a abelha é abelha, e a mera diferença de graus atestada por Aristóteles já esconderia o corte radical, que foi, contudo, naturalizado, na perspectiva de um 'movimento de cada ente para chegar a ser si mesmo' pertencente à noção aristotélica de natureza" ("Aristóteles e Agamben: alguns apontamentos sobre a transmissão do vínculo entre logos e pólis", p. 259-260)

${ }^{29}$ CASSIN, Aristóteles e o logos: contos da fenomenologia do comum, p. 49. Nesse sentido Barbara Cassin cita uma passagem exemplar: "São políticos aqueles para quem se constitui certa unidade e uma comunidade, partilhada por todos, no domínio da obra - o que, precisamente, nem todos os que vivem em grupo fazer. Mas é o caso do homem, da abelha, da vespa, da formiga, do corvo" (ARISTÓTELES, apud CASSIN, Aristóteles e o logos: contos da fenomenologia do comum, p. 49).

${ }^{30}$ AGAMBEN, “O fim do pensamento”, p. 145. 
sons vocais são o signo da dor ou do prazer, e é por isso que pertencem aos outros animais; sua natureza, com efeito, se limita a ter a sensação de dor e de prazer, e significá-los uns para os outros. Mas o logos é feito para manifestar o útil e o prejudicial, e por consequência o justo e o injusto; tal é com efeito o próprio dos homens em relação aos outros animais: serem os únicos a ter a sensação do bem e do mal, do justo e do injusto, e do restante; ora, a reunião dessas sensações constitui a casa e a cidade. ${ }^{31}$

Esse trecho retirado da Política de Aristóteles e comentado por Agamben não deixa dúvidas de que o filósofo italiano compreende em toda a profundidade que "o texto aristotélico lança para o pensamento por vir a demanda por encontrar o vínculo essencial, o modo como se entrelaçam e imbricam, no homem, ter a linguagem e ser um vivente político". 32 É por isso que não nos surpreende tanto que em Homo sacer, encontremos tantas passagens em que mesmo tratando de temas referentes ao direito a linguagem seja evocada sempre de modo central. Como veremos, Agamben avança na importância da linguagem não apenas no sentido de compreender o fundamento linguístico da política, mas também o lugar e a estrutura do próprio direito. Isso porque ele detecta uma analogia fundamental entre essa relação do homem com o logos e a principal operação jurídico-política de nossa tradição: “A ex-ceptio, a exclusão inclusiva do real com relação ao logos e no logos, é, portanto, a estrutura originária do acontecimento da linguagem". ${ }^{33}$ É precisamente sobre essa operação fundamental que passaremos a tratar agora.

Um dos melhores, mas também mais enigmáticos, exemplos dessa sobreposição de planos - entre o plano da linguagem e o plano da política/direito - em Agamben pode ser extraída de Homo sacer:

Hegel foi o primeiro a compreender em profundidade esta estrutura pressuponente da linguagem, graças a qual ela está, ao mesmo tempo, fora e dentro de si mesma, e o imediato (o não-linguístico) se revela como nada além de um pressuposto da linguagem. "O elemento perfeito" - ele escreveu na Fenomenologia do espirito - "em que a interioridade é tão exterior quanto a exterioridade é interna, é a linguagem" (Hegel, 1971, v. III, p. 527-529). Como somente a decisão soberana sobre o estado de exceção abre o espaço no qual pode se traçar os confins entre interno e externo, e determinadas normas podem ser atribuídas a determinados territórios, assim somente a língua como pura potência de significar, retirando-se de toda concreta instância de discurso, divide o linguístico do não-linguístico e permite a abertura de âmbitos de discurso significantes, nos quais a certos termos correspondem certos denotados. A linguagem é o soberano que, em permanente estado de exceção, declara que não existe um fora da língua, que ela está sempre além

${ }^{31}$ ARISTÓTELES, apud CASSIN, “Aristóteles e o logos: contos da fenomenologia do comum”, p. 50

${ }^{32}$ FRANCALANCI, “Aristóteles e Agamben: alguns apontamentos sobre a transmissão do vínculo entre logos e polis", p. 261.

33 AGAMBEN, O uso dos corpos, 296. 
de si mesma. A estrutura particular do direito tem seu fundamento nesta estrutura pressuponente da linguagem humana. Ela exprime o vínculo de exclusão inclusiva ao qual está sujeita uma coisa pelo fato de encontrar-se na linguagem, de ser nominada. Dizer, neste sentido, é sempre ius dicere. ${ }^{34}$

O que temos nesse trecho é a demonstração da operação de um mesmo dispositivo ${ }^{35}$ em dois âmbitos distintos. O soberano, que na definição de Carl Schmitt corresponde àquele que decide sobre o estado de exceção, atuaria tanto na linguagem quanto no direito. Mas como isso é possível? Como esse trecho parece indicar, a reflexão sobre o direito em Agamben tem um alcance, e talvez até um alvo, que não se reduz apenas ao direito ou à política. O leitor de Homo sacer que não tem uma leitura de outros textos de Agamben é pego de surpresa, num aparente deslocamento de categorias político-jurídicas para a descrição de um âmbito linguístico e, talvez até mais do que isso, para a descrição da própria condição humana enquanto ser que "possui", ou melhor, que se relaciona com a sua língua. É o que também podemos ser levados a pensar quando Agamben se refere a um "estado de exceção linguísticos"36. Apesar disso, não podemos nos deixar enganar: a exceção soberana, em Agamben, não pode ser apenas uma estrutura do direito. Trata-se, antes, de uma estrutura da própria linguagem humana, uma estrutura funcional, que mostra que a validade (existência), tanto do sistema linguístico quanto do sistema jurídico, independe da efetiva aplicação ao caso concreto, isto é, independe da significação ou de sua eficácia. A existência de um e de outro, quer dizer, o que garante a existência e validade, respectivamente, da linguagem e da lei, é antes a criação do próprio âmbito de referência sobre o qual eles podem incidir. É por isso que também encontramos na citação o paralelo entre as "normas" que se aplicam sobre "territórios" e os "termos" que se aplicam aos "denotados". A existência (ou validade) de ambos, portanto, não reside em sua aplicação, mas em sua aplicabilidade, i. e., na mera possibilidade de ser aplicado (enforced). Numa analogia com as categorias aristotélicas, poderíamos dizer que o momento privilegiado está na potência, e não no ato. É a virtualidade presente na lei e na linguagem que os define, e não sua atualização. Portanto, no caso do direito, a existência da lei prescinde de sua aplicação. De forma análoga, a palavra prescinde de sua significação ou de sua denotação para existir. Tanto o direito quanto a linguagem, portanto, são regidos pelo que Agamben denomina "estrutura pressuponente da linguagem", de modo que existem e funcionam (isto é, podem ou não passar ao ato) a partir da existência de um imediato (irrelato), não jurídico ou não linguístico, respectivamente ${ }^{37}$.

É esse tipo de comparação que nos leva a crer na possibilidade de encontrarmos em Agamben elementos para pensar um fundamento linguístico do direito. Talvez, ao contrário do que nosso pensamento político tradicional esteja acostumado a pensar, a arché da soberania e da exceção e, sobretudo, a estrutura do direito e da política, não possam ser

34 AGAMBEN, Homo sacer: o poder soberano e a vida nua, pp. 28-29.

35 Para o conceito de dispositivo, Cf. AGAMBEN, "O que é o dispositivo?"

36 AGAMBEN, Homo sacer: o poder soberano e a vida nua, p. 32.

${ }^{37}$ Há já aqui uma clara ressonância com o pensamento de Thomas, que segundo Agamben pensa que " $\mathrm{A}$ 'coisa' do direito não é uma coisa, mas uma operação que a qualifica e a constitui, incluindo-a no direito através de uma exclusão" (AGAMBEN, “Trai il diritto e la vita”, p. 16. Tradução nossa). 
explicadas a partir de si mesmas. Pelo menos de um ponto de vista filosófico, o que Agamben parece querer mostrar é que a estrutura da exceção, da exceptio, é um mecanismo constituído já no momento da captura do próprio vivente pela linguagem. É isso, ao menos, o que Agamben parece indicar desde o início até o fim da série Homo sacer. Um dos argumentos que corrobora nossa hipótese parte da seguinte afirmação feita em $O$ uso dos corpos, último volume da série Homo sacer: "é possível, de resto, que o mecanismo da exceção seja constitutivamente

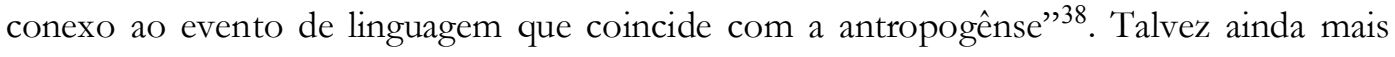
elucidativa sobre a relação entre linguagem e o pensamento ético, político e jurídico de Agamben seja a seguinte afirmação:

A estrutura originária da política ocidental consiste em uma ex-ceptio, em uma exclusão inclusiva da vida humana na forma da vida nua. Reflita-se sobre a especificidade dessa operação: a vida não é política em si mesma - por isso, ela deve ser excluída da cidade; contudo, é justamente a exceptio, a exclusãoinclusiva desse Impolítico que fundamenta o espaço da política ${ }^{39}$

Em A ideia da linguagem, publicado em 1984 - portanto praticamente 10 anos antes da publicação de Homo sacer e um ano antes da publicação de $A$ linguagem e a morte - já podemos encontrar, num ambiente completamente estranho à reflexão jurídico-política de Agamben, a estrutura da exceptio. Num contexto de subversão do argumento da prova ontológica da existência de Deus por Santo Anselmo, Agamben afirma que só há "um ser do qual a simples nomeação linguística implica a existência, e esse ser é a linguagem" ${ }^{40}$. Porém, segundo Agamben, mais uma correção ao argumento de Santo Anselmo seria necessária para que o argumento ontológico fosse correto: mesmo se admitirmos que "Deus" seja o nome da linguagem, ainda seria preciso subtrair a abertura do mundo provocada pela existência de "Deus" da esfera do discurso significante. Para isso, Agamben recorre ao lógico medieval Gaunilo que, em sua refutação do argumento de Santo Anselmo, recorre ao "pensamento da voz só" (cogitatio secundum vocem solam). O pensamento da voz indica que a linguagem não se reduz à significação; indica que há uma dimensão que precede logicamente a significação, isto é, que não significa nada além da abertura que torna a significação possível. A única coisa que o pensamento da vOz pode significar é significação. Reivindicando o lugar de uma experiência "já não de um mero som e ainda não de um significado" 41 , o pensamento da vOz mostra que a linguagem tem a mesma estrutura da revelação (como já argumentamos acima), mas também que ela possui a mesma estrutura da lei: a peculiar capacidade de estar em vigor sem necessariamente significar parece ser aquilo que toca o segredo mais íntimo (o mistério) da linguagem e da lei. Conforme observamos em Homo sacer, a capacidade da lei de suspender a si mesma é o que a constitui como lei. Ao se autossuspender, a lei entraria num estado que Agamben, na esteira da interpretação feita por Scholem do processo kafkiano, afirma como sendo o da "vigência sem significado". É em vista desse particular "vigor" da lei, dessa sua

38 AGAMBEN, Uso dos corpos, p. 296.

39 AGAMBEN, Uso dos corpos, p. 295.

${ }^{40}$ AGAMBEN, $A$ ideia da linguagem, p. 25.

${ }^{41}$ AGAMBEN, A ideia da linguagem, p. 26. 
capacidade de continuar vigente, embora sem produzir seus efeitos, que a lei é constituída como lei.

Agamben retoma essa estrutura da linguagem, comum também à estrutura da lei, a partir do conto Diante da lei, de Kafka. A interpretação de Agamben destaca a entrega do camponês - que se vê diante da porta aberta para si - como uma entrega à potência própria e máxima da lei. A lenda narrada por Kafka mostra nada menos que a estrutura da lei corresponde ao modelo da exceção soberana. O intuito de Kafka, segundo Agamben, é o de denunciar que justamente no ponto em que a lei não prescreve mais nada, isto é, no momento em que a lei se mostra em sua forma pura, como potência pura, é que ela se afirma com mais força ${ }^{42}$. Nesse sentido, conclui Agamben que "o nosso tempo está, de fato, defronte da linguagem como, na parábola, o camponês está diante da porta da lei”,43.

É apenas quando confrontados com a simetria entre a estrutura da linguagem e a estrutura da lei que algumas definições de Agamben podem ser entendidas. Esse é o caso de uma definição presente em Meios sem fim:

[soberania e poder constituinte] assinalam o ponto de indiferença entre violência e direito, natureza e logos, próprio e impróprio e, como tais, não designam um atributo ou um órgão do ordenamento jurídico ou do Estado, mas a sua própria estrutura original. Soberania é a ideia de que haja um nexo indecidível entre violência e direito, vivente e linguagem, e que tal nexo tenha necessariamente a forma paradoxal de uma decisão sobre o estado de exceção (Schmitt) ou de um bando (Nancy), em que a lei (a linguagem) se mantém em relação com o vivente retirando-se dele, a-bandonando-o à sua própria violência e à sua própria irrelatez..$^{44}$.

Mas a equivalência entre a estrutura da lei e a estrutura da linguagem possui ainda outras semelhanças. Uma delas diz respeito ao elemento que mantém o vivente preso à lei, que é abordado por Agamben a partir da noção de culpa. O uso da noção de culpa para descrever o vínculo do homem ao direito serve para reforçar que assim como a potência da lei não se define por sua aplicação, também a captura da vida pelo direito independe da transgressão. A culpa, segundo Agamben, "não se refere à transgressão, ou seja, à determinação do lícito e do ilícito, mas à pura vigência da lei, ao seu simples referir-se a alguma coisa" 45 . Em Mysterium burocraticum encontramos novamente a menção do nexo entre culpa e pena a partir do nexo da ideia culpada da linguagem e a forma jurídica: "'tomar o nome', nomear a si mesmo e as coisas significa poder a si e a elas conhecer e dominar; mas significa, ao mesmo tempo, submeter-se às potências da culpa e do direito"46.

Em O sacramento da linguagem: arqueologia do juramento, um dos livros que compõe a série Homo sacer, Agamben dá um passo decisivo na explicação de como a linguagem humana se

42 AGAMBEN, Homo sacer: o poder soberano e a vida nua, p. 55.

${ }^{43}$ AGAMBEN, Homo sacer: o poder soberano e a vida nua, p. 59.

44 AGAMBEN, Meios sem fim: notas sobre a politica, p. 104.

45 AGAMBEN, Homo sacer: o poder soberano e a vida nua, p. 33 (grifos do autor).

46 AGAMBEN, Il fuoco e il racconto, p. 22 (tradução nossa). 
relaciona com as instituições culturais dos homens - direito, mas também religião, poesia e literatura - de uma forma constitutiva. A mesma estrutura da lei de estar em "vigência, sem significar" aparece novamente como uma característica da linguagem humana, agora, no entanto, sob a forma de uma característica do logos que permite a performatividade da linguagem do homem. Suspendendo sua denotação, a linguagem é capaz de ser performativa, isto é, de suspender sua denotação para fundar a sua relação com o mundo ${ }^{47}$. À luz da noção de performatividade linguística, o filósofo afirma que: "importa inverter mais uma vez a eficácia comum que explica a eficácia do juramento remetendo-o às potências da religião e do direito sagrado arcaico. Religião e direito não preexistem à experiência performativa da linguagem" ${ }^{48}$. Desenvolvendo essa tese, o filósofo afirma que o direito e a religião foram inventados para assegurar a verdade e a confiabilidade da linguagem humana ${ }^{49}$. Caberia à filosofia a salvaguarda da experiência performativa da linguagem, a partir da qual algo como o direito e a religião são possíveis. Nesse sentido, Agamben parece seguir as intuições fundamentais do seu já falecido amigo, com quem teria tido desde 1996, como ele mesmo relata ${ }^{50}$, inúmeras conversas: Yan Thomas. Para Thomas, o mundo social é posto em forma por meio de operações linguísticas e a potência específica do direito no mundo social é a de produzir o mundo que designa ${ }^{51}$. Essa visão do direito sustentada por Thomas parece se integrar à visão de Agamben sobre o direito até as últimas consequências: o direito é a linguagem mais eficaz que a linguagem em geral do homem e nesse sentido detém um poder de transformação sem igual. A eficácia da linguagem jurídica é devedora dessa relação performativa primordial resultante de uma suspensão primeira de sua denotação. É uma máquina de abstração que pela linguagem produz o real. É um produto que opera por ficções ${ }^{52}$ - portanto integralmente construído e artificial - que é possível graças ao caráter performativo da linguagem. Comentando Thomas, Spanò afirma que "o direito é uma prática discursiva única: e nela, por assim dizer, abriga a potência mesma da linguagem" 53 . Em $O$ sacramento da linguagem, portanto, Agamben parece de fato subscrever completamente às teses de Thomas sobre a relação entre linguagem e direito. Além disso, nesse mesmo livro, encontramos na noção de performatividade um conceito que, apesar de tardio na obra de Agamben, parece dar conta de explicar uma série de relações que o filósofo estabelece entre linguagem e política, mas também linguagem e ética e linguagem e direito.

47 As reflexões de Agamben sobre o comando e sobre a forma imperativa do verbo são esclarecedoras da performatividade da linguagem. Cf. AGAMBEN, Qu'est-ce que le commandement?.

48 AGAMBEN, O sacramento da linguagem: arqueologia do juramento. p. 69

49 Agamben opõe asserção e veridicção, afirmando que do cuidado com o aspecto assertório do logos nascem a lógica e as ciências, ao passo que da veridicção proveriam o direito, a religião, a poesia e a literatura (AGAMBEN, O sacramento da linguagem: arqueologia do juramento, p. 70).

${ }^{50}$ AGAMBEN, "Trai il diritto e la vita", p. 10.

${ }^{51}$ SPANÒ, "Le parole e le cose (del diritto)", p. 88-89.

52 No que diz respeito à noção de ficção em sua obra, Agamben afirma que "nos termos de Yan, a vida nua é a fictio cuja exclusão assegura ao direito a captura da sua vida, assim como o estado de exceção é o dispositivo através do qual o ordenamento jurídico, suspendendo temporariamente a sua vigência, determina o âmbito normal de sua validade. A vida nua e o estado de exceção, como todo resultado de uma operação jurídica, são uma abstração, e não uma realidade substancial" (AGAMBEN, “Tra il diritto e la vita", p. 17).

${ }^{53}$ SPANOे, "Le parole e le cose (del diritto)", p. 90. 


\section{CONCLUSÃO}

Ao longo do nosso artigo pretendemos ter mostrado que o tema primeiro de Agamben é a linguagem, ou melhor, o que ele chama de experimentum linguae. Pretendemos ter defendido duas coisas: em primeiro lugar, que a linguagem constitui o fio condutor de todas as demais investigações de Agamben, sejam elas sobre a estética, a teologia, a tradição, a política, a ética ou o direito; em segundo lugar, que Agamben radicaliza o lugar da relação entre o homem e o logos na experiência Ocidental.

Nesse sentido, dividimos o trabalho em duas partes. Na primeira parte pretendemos ter mostrado, sobretudo a partir de textos anteriores à série Homo sacer, especialmente os presentes na coletânea A potência dopensamento, de que forma o pensamento sobre a linguagem influencia a compreensão de Agamben sobre o conceito de filosofia, de teologia e de tradição. Já na segunda parte pretendemos ter mostrado de que forma a operação jurídico-política fundamental de nossa tradição de acordo com Agamben está vinculada de forma necessária com a forma como pensamos até hoje a relação do homem com o logos. Para Agamben, a estrutura de exceptio corresponde à estrutura originária do acontecimento de linguagem. Desse modo, também compreendemos que ao nos debruçarmos sobre os textos de Agamben é impossível distinguirmos seus trabalhos em disciplinas separadas. Logo, se a partir de meados dos anos 1990 Agamben se voltou mais explicitamente à temática da política e do direito, isso só pode ser compreendido em sua radicalidade a partir de suas análises precedentes, o que inviabiliza a divisão da obra do autor em fases ou temas.

\section{ON LANGUAGE AS THE COMMON THREAD OF GIORGIO AGAMBEN'S REFLECTIONS}

Abstract: The article intends to approach language as the fundamental engine of Giorgio Agamben's reflections, whether pertinent to philosophy, theology, law or politics. To accomplish this purpose the article is divided into two parts. In the first one, we intend to show, especially from texts prior to the series Homo sacer, especially those present in the collection Potentialities: Collected Essays in Philosophy, in what way the thinking on language influences Agamben's understanding of the concept of philosophy, theology and tradition. In the second part we intend to explore in what way, according to Agamben, the fundamental juridical-political operation of our tradition is linked to the way we think until today the relation of man and logos. For Agamben, the exceptio structure corresponds to the original structure of the language event.

Keywords: language - politics - law - exception.

\section{REFERÊNCIAS BILIOGRÁFICAS}

AGAMBEN, G. "A coisa mesma”. In: - A potência do pensamento: ensaios e conferências. Belo Horizonte: Autêntica, 2015.

AGAMBEN, G. “A ideia da linguagem”. In: - Apotência do pensamento: ensaios e conferências. Belo Horizonte: Autêntica, 2015. 
AGAMBEN, G. A linguagem e a morte: um seminário sobre o lugar da negatividade. Belo Horizonte: UFMG, 2006.

AGAMBEN, G. "A potência do pensamento". In: . Apotência do pensamento: ensaios e conferências. Belo Horizonte: Autêntica, 2015.

AGAMBEN, G. Estâncias: a palavra e o fantasma na cultura ocidental. Belo Horizonte: UFMG, 2012.

AGAMBEN, G. "Filosofia e linguística. Jean-Claude Milner: Introduction à une Science du langage." In:__. A potência do pensamento: ensaios e conferências. Belo Horizonte : Autêntica, 2015.

AGAMBEN, G. Homo sacer: o poder soberano e a vida nua. Belo Horizonte: UFMG, 2010.

AGAMBEN, G. Infância e história: destruição da experiência e origem da história. Belo Horinzonte: UFMG, 2005.

AGAMBEN, G. O uso dos corpos. São Paulo: Boitempo, $2017 \mathrm{~b}$.

AGAMBEN, G. "Língua e história: categorias linguísticas e categorias históricas no pensamento de Walter Benjamin”. In: - A potência do pensamento: ensaios e conferências. Belo Horizonte: Autêntica, 2015.

AGAMBEN, G. Meios sem fim: notas sobre a política. Belo Horizonte: Autêntica, 2015.

AGAMBEN, G. "Mysterium burocraticum”. In: Il fuoco e il racconto. Roma: Nottetempo, 2014.

AGAMBEN, G. “O que é o dispositivo?” In: O que é o contemporâneo? e outros ensaios. Tradução Vinícius Nicastro Honesko. Santa Catariana: Argos, 2009

AGAMBEN, G. O sacramento da linguagem: arqueologia do juramento. 2011, p. 70.

AGAMBEN, G. "O fim do pensamento". In: . A linguagem e a morte: um seminário sobre o lugar da negatividade. Belo Horizonte: UFMG, 2006.

AGAMBEN, G. "Principia hermenêutica”. In: Critique, Paris: Éditions Minuit 2017/1 n836-837, pp. $5-13$.

AGAMBEN, G. "Sobre os limites da violência". Revista Sopro: panfleto político-cultural. Out/2017a. N $\mathrm{N}^{\mathrm{0}} 79$.

AGAMBEN, G. Qu'est-ce que le commandement? Paris: Payos \&Rivages, 2013.

AGAMBEN, G. Signatura rerum: sur la méthode. Paris: Vrin, 2008.

AGAMBEN, G. “'Trai il diritto e la vita”. In: Thomas, Y. Il valore delle cose. Macerata: Quodlibet, 2015.

BARBOSA, J. Política e tempo em Giorgio Agamben. São Paulo: EDUC, 2014.

BENVENISTE, É. Le vocabulaire des institutions indo-européennes. Paris: Minuit, 1969, v. 1 e 2. 
CASTRO, E. Introdução à Giorgio Agamben: uma arqueologia da potência. Belo Horizonte: Autêntica, 2012.

CASSIN, B. Aristóteles e o logos : contos da fenomenologia do comum. São Paulo: Loyola, 1999.

COCCIA, E. “Quodilibet. Logique et physique de 1'être quelconque”, In: Critique, Paris: Éditions Minuit 2017/1 n836-837, pp 66-77.

D’ALONZO, J. Bibliografia di Giorgio Agamben. Disponível em: www.filosofia-italiana.net, Marzo, 2014.

D’ALONZO, J. "El origen de la nuda vida: política y lenguaje en el pensamiento de Giorgio Agamben”. Revista Pléyade 12, julio - diciembre, pp. 99-118, 2013.

FRANCALANCI, C. "Aristóteles e Agamben: alguns apontamentos sobre a transmissão do vínculo entre logos e pólis". O que nos fazpensar. v. 23 n. 35 (2014): № 35: dezembro de 2014.

GERNET, Louis. Recherches sur le développement de la Pensée Juridique et Morale en Grèce: Étude Semantique. Paris: Ernest Leroux, 1917.

GNOLIO, A.; GOVRIN, I. "Philosophy As Interdisciplinary Intensity - An Interview With Giorgio Agamben.” Disponível em: http://jcrt.org/religioustheory/2017/02/06/philosophy-asinterdisciplinary-intensity-an-interview-with-giorgio-agamben-antonio-gnolioido-govrin/. Último acesso 21/03/17.

HEIDEGGER, M. Ser e tempo. Rio de Janeiro: Vozes, 2012.

KARMY, Rodrigo. Políticas de la Excarnación. Para una genealogía teológica de la biopolitica. Buenos Aires: Editorial Universidad Pedagógica. En Prensa.

MILLS, C. The philosophy of Agamben. Montréal: McGilll-Queen’s University Press, 2008.

MURRAY, A. Giorgio Agamben. New York: Routledge critical thinkers, 2010.

SALZANI, C. "Il linguaggio è il sovrano: Agamben e la politica del linguaggio". Rivista Italiana di Filosofia del Linguaggio, 9(1), 2015, pp. 268-280.

SPANÒ, M. "Le parole e le cose (del diritto)". In: THOMAS, Y. Il valore delle cose. Macerata: Quodlibet, 2015, p. 88-89. 